\title{
POLÍTICA, PODER E TOTALITARISMO: UMA ANÁLISE NA PERSPECTIVA DE HANNAH ARENDT
}

\author{
POLITICS, AND POWER TOTALITARIANISM: AN ANALYSIS FROM THE \\ PERSPECTIVE OF HANNAH ARENDT
}

\author{
Ricardo George de Araújo Silva ${ }^{1}$ \\ Napiê Galvê Araújo Silva ${ }^{2}$
}

\section{RESUMO}

O objetivo do texto é discutir o conceito de política a partir das abordagens de Hannah Arendt. A pergunta norteadora da pesquisa é saber qual é a finalidade da política? Para os gregos a política é compreendida como o espaço da ação entre iguais que deliberam sobre a vida comum da polis em condições igualitárias no que concerne o poder de fala e decisão. Não se concebe, portanto nenhuma expressão de violência ou veto a ação e discurso do outro. Arendt (2001a) concorda e ensina que a política tem a finalidade de conduzir os negócios da polis a partir da capacidade dos homens livres de se persuadirem pela palavra. É importante frisar que esse debate em torno da política na atualidade guarda características protototalitárias na medida em que os indivíduos cada vez mais se isolam e assumem uma postura de descompromisso com a coisa pública e se distancia da política, fornecendo terreno fértil para emergência de governos pautados na violência e arbitrariedade. Aqui não se aponta nenhuma receita ou cânone em torno da política, haja vista que seu núcleo duro deva ser o debate entre os homens e mulheres que se interessam pela coisa pública, contudo subjaz a lógica desse debate a preservação da vida, a conservação do existir humano.

Palavras-chave: Política - Liberdade - Igualdade.

\section{ABSTRACT}

The purpose of the paper is to discuss the concept of policy approaches from Hannah Arendt. The guiding question of the research is to know what is the purpose of the policy? For the Greeks the policy is understood as the space action among equals who deliberate about the common life of the polis in equal conditions regarding the power of speech and decision. Not conceivable, therefore no expression of violence or veto the action and discourse of the other. Arendt (2001a) agrees and teaches that the policy has the purpose of conducting the business of the polis from the ability of free men to persuade the word. Importantly, the debate around the policy today features protototalitárias guard in that individuals increasingly isolate themselves and assume a stance of disengagement with public affairs and policy distance, providing fertile ground for the emergence of governments guided violence and arbitrariness. Here there is no recipe or canon points around the policy, given that its core should be the debate between the men and women who are interested in public affairs, 
but the underlying logic of this debate the preservation of life, the preservation of existing human.

Keywords: Politics - Freedom - Equality.

\section{INTRODUÇÃO}

Quando pensamos a questão da política é inevitável um retorno ao mundo clássico, em especial aos gregos. Isto se torna fundamental quando pretendemos separar os eventos que são políticos daqueles que tem a pretensão de políticos, mas que na suas práticas acabam por negar a política.

A política na concepção grega é o espaço da ação entre iguais, ou seja, é relevante que aqueles que deliberam sobre a vida comum da polis estejam em condições igualitárias no que concerne o poder de fala e decisão. Não se concebe, portanto nenhuma expressão de violência ou veto a ação e discurso do outro. Arendt (2001b, p, 13) esclarece que a "faculdade específica do homem é a de conduzir os negócios da polis através da capacidade dos homens livres de se persuadirem pela palavra". Portanto, só pode existir persuasão se houver liberdade e igualdade dos agentes em questão.

Contudo, emerge uma questão, a saber: qual a finalidade da política? Em suma não apontamos nenhuma receita ou cânone em torno da política, haja vista que seu núcleo duro deva ser o debate entre os homens e mulheres que se interessam pela coisa pública, contudo subjaz a lógica desse debate a preservação da vida, a conservação do existir humano.

Conforme Arendt (2002, p, 46) "a tarefa e objetivo da política é a garantia da vida no seu sentido mais amplo" o que nos leva a uma reflexão em torno dos movimentos totalitários do século 20 que se pretenderam políticos. Contudo, o que mais ficou marcante em suas atuações foi à negação da vida e da liberdade. Entendemos que o totalitarismo e seus recursos só podem ser o ineditismo negativo da história da humanidade que afrontou a vida em comum. Este evento nos traz a certeza de que

Ascensão do totalitarismo e dos campos de concentração nos faria testemunhas do radical aniquilamento da liberdade como possibilidade humana e política. $O$ mal radical tinha seu cerne na 
acuidade com a qual o totalitarismo rompia com a nossa própria capacidade de compreender Fenômenos (ASSY, 2001, p, 87. In: Origens do Totalitarismo: 50 anos depois).

Assim, ao nos propormos ao enfrentamento da tríade Política, Poder e, totalitarismo pretendemos uma exposição do fenômeno totalitário no intuito de apresentar o mesmo a parti de seus recursos como a propaganda e a violência para diferenciá-lo de toda e qualquer possibilidade de identificação com a política, considerando os parâmetros acima descritos.

\section{TOTALITARISMO: O RECURSO DA PROPAGANDA}

O século XX ficou marcado como sendo o século da informação; o cinema, o rádio, a televisão, a Internet, tudo isso despontou no século XX e foi utilizado para os mais diversos fins, desde a divulgação de um produto, passando pelo entretenimento, até a construção de imagens, tipos e conceitos, embora, muitas vezes, o que a imagem propagava não correspondesse aos fatos, ou pior, encobrisse o que estava por vir.

Nessa perspectiva, a propaganda foi um recurso fundamental dos movimentos totalitários, principalmente se levarmos em conta o caráter profético ${ }^{3}$ da propaganda totalitária, pois a mesma, sem usar da possibilidade de verificação, prediz algo no intuito de ganhar a adesão das massas. Entretanto, uma vez que esse apoio esteja garantido e, uma vez, que a oposição tenha sido liquidada, a propaganda assume o seu verdadeiro

potencial ideológico e passa a conformar a realidade às suas próprias premissas.

A propaganda totalitária distingue-se da mera demagogia política na medida em que não se satisfaz com a disseminação da mentira, mas, paradoxalmente, transforma a mentira em verdade (DUARTE, 2000, p. 54). Tal transformação objetiva o convencimento e a credulidade das massas, pois é necessário para o movimento totalitário que suas mentiras sejam digeridas como verdade uma vez que as mesmas irão constituir o nexo aglutinador do movimento totalitário.

É sabido que grandes lideres da história se fizeram seguir pelas esperanças que anunciavam e por verdades que satisfaziam seus seguidores. 
Os líderes totalitários, não tendo verdades, propagam mentiras com o tom de verdade e encontram terreno fértil na sociedade de massas, desenraizada e isolada, que passa a assumir qualquer ideologia como sua. Não se identifica, pois, no artifício totalitário da propaganda, nenhuma preocupação ética com a seriedade dos fatos propagados. Ao contrário, divulgam-se ideologias do tipo "toda a historia é a história da luta de classes, que o proletariado está ligado a leis eternas para vencer essa luta, que uma sociedade sem classe virá e que o estado, finalmente, desaparecerá", de modo que Arendt conclui:

\begin{abstract}
As ideologias sempre se orientam na direção da história, mesmo quando, como no caso do racismo, parecem partir da premissa da natureza; nesse caso, a natureza serve apenas para explicar as questões históricas e reduzi-las a elementos da natureza. A pretensão de explicação total do passado, o conhecimento total do presente e a previsão segura do futuro (ARENDT, 1998, p. 523).
\end{abstract}

O meio mais eficaz que o totalitarismo encontrou para fazer valer sua "verdade" foi o terror. Esse passou a ser o principal argumento, isto é, foi utilizado um monólogo para legitimar as ideologias totalitárias, já que os métodos do terror não permitem um contraponto. O terror foi, assim, o maior aliado da propaganda totalitária, legitimando a mesma e dando a ela condições de se perpetuar no tempo, sem a possibilidade de uma verificação mais séria a tal ponto se confundem que, nos países totalitários, a propaganda e o terror parecem ser duas faces da mesma moeda (ARENDT, 1998, p. 390).

O fato do movimento totalitário não se encontrar em um mundo totalitário levou o movimento a usar da propaganda como recurso para introduzir suas ideologias e mentiras, como esperanças e verdades últimas a ser seguidas e defendidas. Quando chega ao poder não abandona tal estratégia, mas a mantém nem que seja para atingir a quem ainda não foi suficientemente doutrinado. Nesse ponto, os discursos de Hitler aos seus generais, durante a guerra, são verdadeiros modelos de propaganda, caracterizados principalmente pelas monstruosas mentiras com as quais 0 Führer entretinha seus convidados na tentativa de conquistá-los (ARENDT, 1998, p. 392).

Hannah Arendt chama a atenção para a peculiaridade da propaganda totalitária, que encontra motivação na pressão externa, pois os 
movimentos por si mesmos, em vez de se propagarem, doutrinam (ARENDT, 1998, p. 393). Isso nos leva a constatar o papel da propaganda totalitária como construtora de imagens e de um ideal a ser seguido, tanto quanto de modeladora de posturas. Esse último papel realizado pelo terror que, como parte integrante da "guerra psicológica", consegue ser mais eficaz que a propaganda. Tanto é que, mesmo depois de alcançados os objetivos, o terror continua a ser aplicado pelos regimes totalitários. De modo que,

Onde o reino do terror atinge a perfeição, como nos campos de concentração, a propaganda desaparece inteiramente; na Alemanha nazista, chegou a ser expressamente proibida. Em outras palavras, a propaganda é um instrumento do totalitarismo, possivelmente o mais importante, para enfrentar 0 mundo não totalitário. O terror, ao contrário, é a própria essência de sua forma de governo (ARENDT, 1998, p. 393).

A partir desse relato fica mais clara a distinção entre o papel da propaganda e o papel do terror. A propaganda aparece como instrumento importante, central, mais um instrumento, o que significa que pode ser deixado de lado quando não mais necessário. $O$ terror, por sua vez, assume o caráter essencialista, apresenta-se como marca indelével da ação totalitária, onde não importa o estágio em que se encontre o totalitarismo: se no inicio ou se já solidificado, o terror continuará presente.

A propaganda, como importante recurso do movimento totalitário, traça estratégias que ganham conotação de publicidade, na medida em que tenta despertar, no público-alvo, sentimentos de crença, ansiedade e medo usando expressões de ameaça: se não "comprarem" tal idéia. Agem, como quem incute verdades no processo de doutrinação. $O$ dito, o anunciado, apresenta-se como uma necessidade e ganha contornos "científicos" de modo que é difícil ao grande público separar o que é real e o que é exagero. No caso das massas, o mais cômodo é optar pela aceitação do que é propagado.

Nesse sentido, o cientificismo aí utilizado aparece como substituto do poder, sendo abandonado logo que o totalitarismo assuma o poder. Tudo isso com insinuações do tipo: "vocês irão perder o trem da história e irão se atrasar irremediavelmente em relação ao tempo, ao esbanjarem sua vida inutilmente" - tal como fazia a propaganda comunista -, ou ainda, no modelo nazista, que com um simples lema - "de outra forma pereceremos" - é capaz 
de levar um povo à guerra (ARENDT, 1998, p. 397). Dessa maneira, o uso da propaganda pelo totalitarismo é essencialmente uma estratégia-chave para o êxito de seus objetivos. É óbvio que ela não é suficiente para alcançar o domínio total, logo o totalitarismo usa outro recurso, a violência.

\title{
A VIOLÊNCIA TOTALITÁRIA: O BRAÇO DO TERROR
}

A descrição abaixo mostra todo o horror vivido pelos judeus nos campos de concentração os quais trouxeram à tona toda a capacidade de destruição sistemática do regime totalitário, tanto quanto o mesmo apresentou seu principal método de atuação, a violência:

\begin{abstract}
Nas fábricas da morte [...]. Todos eles morreram juntos, os jovens e velhos, os fracos e fortes, os doentes e os saudáveis; não como povo, não como homens e mulheres, crianças e adultos, meninos e meninas, não como bons e maus, belos e feios, mas reduzidos ao denominador comum do mais baixo nível da vida orgânica em si mesma, mergulhados no abismo mais escuro e profundo da igualdade primitiva, como gado, como matéria, como coisa sem corpo nem alma, sem nem mesmo uma fisionomia sobre a qual a morte pudesse imprimir seu selo. É nessa igualdade monstruosa, sem fraternidade ou humanidade [...], que nós vemos, como que refletida, a imagem do inferno. A maldade grotesca daqueles que estabelecem tal igualdade está para além da capacidade de compreensão humana. Mas igualmente grotesca e para além do alcance da justiça humana está a inocência daqueles que morreram nesta ingenuidade. A câmara de gás foi mais do que qualquer um poderia ter merecido, e, frente a ela, o pior criminoso era tão inocente quanto um recémnascido (apud, DUARTE, 2000, p. 61).
\end{abstract}

O extermínio silencioso produzido pelas fábricas da morte reduz 0 significado da existência humana a um nada, em que ser ou não $\operatorname{ser}^{4}$ não tem significado. Para a crueldade nazista, a descartabilidade do outro era algo certo e necessário de tal forma que o extermínio em massa não reflete sobre o significado da existência do outro e, atropelando todos os princípios, cria uma fábrica de cadáveres, para pôr em frente seu objetivo de domínio total, este que é concebido como meta fundamental, tão fundamental que a vida humana passa a ser secundária em nome do objetivo a ser alcançado.

Nessa perspectiva, a violência totalitária atua resguardada pelo Estado, ou seja, o Estado aparece aí como fachada, que possibilita ao monstro ${ }^{5}$ liberar seus tentáculos. Usando sua política secreta e agindo sob 
suas próprias insígnia e vontade, "este [o líder] decide sobre quais categorias sociais incidirão os conceitos de inimigo objetivo ou de sociedade indesejável, tipologias que designam aqueles cuja existência implica discordância para com a ideologia totalitária, merecendo ser exterminados independentemente do que pensem" (DUARTE, 2000, p. 65).

Esse proceder nos leva à compreensão como o sistema totalitário é capaz de destruir o "humano construído nos indivíduos", a tal ponto de vítima e carrasco serem atingidos, pois, na medida em que o campo de concentração anula a liberdade de alguns e produz uma matança sistemática de outros, não apenas as vitimas são desumanizadas, mas executores perdem também o sentido da dignidade humana, fato esse que nos revela a forte característica de novidade do totalitarismo, tanto quanto nos esclarece o seu poder de destruição. Nesse sentido, os campos de concentração se apresentam como a principal instituição dos regimes totalitários, não apenas porque eles condensam e potencializam todos os absurdos implementados, na tecitura do social, por essa forma de dominação sem precedentes, mas, também, porque justamente aí se manifesta o objetivo crucial do totalitarismo: a destruição da infinita pluralidade e diferenciação dos seres humanos.

A violência produzida nos campos de concentração ganhou dimensões inimagináveis. É possível afirmar que até os mais competentes roteiristas de filmes de guerra ou literatos do gênero não tenham, até então, colocado em suas obras tamanho requinte de crueldade e horror, como fez o totalitarismo nos campos de concentração e, nas câmaras de gás. Essa violência manifesta, sobretudo um novo desafio para a compreensão da política, na medida em que as categorias da modernidade se mostram inadequadas ou insuficientes para dar conta de tamanha ruptura que se apresenta na história da humanidade.

A violência totalitária é apolítica na medida em que não permite ao outro o direito de manifestar-se. Até as antigas tiranias eram capazes de se encantar com o discurso contrário as suas práticas ${ }^{7}$ e até aderir a posições daqueles que em algum momento se apresentaram como inimigo político.

No totalitarismo, tal fato é inviável já que o outro não tem direito a compor o tecido social, sendo enviado a confinamentos que destroem sua humanidade ou são diretamente exterminados em câmaras de gás ou com 
outros recursos, contanto que sejam silenciados. O lugar que ocupa o silêncio no modo de agir do totalitarismo tem significado ímpar, tendo em vista que a capacidade do discurso é sempre uma ameaça. O silêncio ganha importância, o mesmo só deve ser quebrado para exaltar os objetivos do movimento totalitário, o líder e seus símbolos.

Portanto, o discurso no totalitarismo tanto é mudo, na medida em que é controlado e direcionado, quanto carente de significado e de poder de denúncia. $O$ único discurso que sobrevive é o do regime totalitário. Fora esse os outros ou se enquadram ou experimentam um último diálogo nos campos de concentração ou câmaras de gás.

Os campos de concentração trouxeram como novidade uma total falta de finalidade, isto é, apresentavam um caráter despropositado em seu agir, "tinham que se financiar a si mesmos e eram praticamente destituídos de qualquer produtividade econômica ou de qualquer finalidade política clara e imediata. Por certo, criminosos e opositores ao regime também foram neles encarcerados, mas a verdadeira natureza dos campos não pode ser compreendida recorrendo-se a esse fato, já que eles só se tornaram abundantes, tanto na Alemanha quanto na União soviética, uma vez sufocada toda oposição. Do mesmo modo, os seus internos, em ambos os países, foram várias vezes obrigados a cumprir trabalhos forçados em regime de escravidão, - que ainda poderia ser humanamente compreensível, pois apresentava precedente histórico. Entretanto, a própria falta de planejamento e de organização dessas tarefas forçadas, somada ao fato de que o trabalho jamais constituiu a regra geral no sistema 'concentracionário', denuncia a verdadeira destinação dos campos de concentração: a de não servirem para coisa alguma, senão para destruição da liberdade" (DUARTE, 2000, p. 68).

A negação e anulação da liberdade humana promovida pelos campos de concentração criaram um clima de destruição do homem, isto é, daquilo que faz o ser humano ser humano. Artifícios como a liberdade, a pluralidade e a existência de um espaço de convivência política garantem humanidade, enquanto a ausência desses nos leva em direção contrária ${ }^{8}$, mutilando a dignidade humana ou até destruindo-a por inteira.

A violência dos campos de concentração traz no seu interior tamanha força destrutiva, que é capaz de aniquilar o último resíduo humano 
presente no homem, transformando-o em mero "feixe de reações" (ARENDT, 1998, p. 492) que, por sua vez, pode ser aniquilado sem oferecer qualquer resistência. Tudo isso torna claro que a violência encontra morada nos campos de concentração. Sendo ela "senhora-mor" dessa casa de horrores, conduz forçadamente cada um de seus habitantes, que aí se encontram, a uma certeza: sua dignidade como pessoa está marcada para sempre ${ }^{9}$, pelo menos a dos que sobrevivem.

\section{TOTALITARISMO: VIOLÊNCIA E PODER}

As marcas deixadas pelos elementos do totalitarismo atingem a vida social e política com a pretensão de instituir poder. As categorias violência e poder durante toda a história do pensamento aparecem como categorias inerentes à política. As reflexões de Hannah Arendt são as primeiras a pôr em dúvida esse binômio violência-poder como par de categorias correlatas. A ruptura provocada pelo regime totalitário demonstra, na análise de Hannah Arendt, que toda ação pautada na violência é, em si, destruidora do sentido da política. $^{10}$

Nessa perspectiva, campos de concentração e câmaras de gás são instrumentos negadores da política. É evidente que, para o totalitarismo, o uso desses recursos eram indispensáveis à realização do seu projeto de domínio total. Contudo, é preciso observar que compreender o conceito de violência e o conceito de poder, nesse âmbito, traz implicações como a negação da liberdade, da pluralidade e do espaço político comum a todos.

A violência empregada pelo totalitarismo "tem um caráter instrumental” (LAFER, 1979, p. 118). O mundo totalitário se apropriou do avanço da ciência em nome da destruição do diferente e do plural. A experiência vivida em Auschwitz exemplifica o uso da violência e todo seu desproposito. Atitudes como as praticadas pelo totalitarismo assustam pela força com que marcaram a história da humanidade, bem como pelo ineditismo, pois jamais se esperava que tamanha crueldade pudesse freqüentar os palcos da vida. Mais grave ainda é a constatação de Arendt que toda violência produzida não gerou culpa ou arrependimento nos autores, mas foi até o fim como uma bandeira para estes, o que levou Arendt a cunhar o conceito de 
"Banalidade do Mal"11, que chegou a Arendt pelas palavras de Eichmann ${ }^{12}$ antes de morrer: "...Este é o destino de todos os homens. Viva a Alemanha, viva a Argentina, viva a Áustria". Eichmann, segundo Arendt, era um homem comum e até medíocre, e que se escondeu de sua responsabilidade criminal atrás de frases como: "apenas cumpria ordens" (LAFER, 1979, p. 140).

O horror totalitário nos leva à compreensão do quanto são inconciliáveis a concepção de poder e a de violência, ainda que uma tradição, seguida, por exemplo, por Weber, dê crédito a essa relação, a tal ponto

de existir um consenso entre os teóricos da política de esquerda e de direita, no sentido de que a violência é tão somente a mais flagrante manifestação do poder. Toda a política é para eles uma luta pelo poder, onde a forma básica do poder é a violência [...] (ARENDT, 2001a, p. 31).

"A definição de Max Weber do Estado como o domínio do homem pelo homem baseado nos meios da violência legitima" (ARENDT, 2001a, p. 31.) aparece como o ponto alto da contradição do consenso a respeito dessa questão. Digo "contraditório" na medida em que levo em consideração a compreensão arendtiana de poder como sendo "o agir em conjunto" (LAFER, 1979, p. 118). O poder é, portanto, a capacidade de pertencer a um grupo ${ }^{13}$, e este só subsiste enquanto subsistir o grupo potestas in populo (sem um povo ou grupo não há poder).

Nessa perspectiva, a pluralidade aparece como categoria central para a compreensão do que seja poder, na medida em que a pluralidade comporta os iguais e os diferentes, possibilita a todos se manifestar como grupo, contudo surge uma questão: um grupo não poderia impor a todos sua vontade? Para compreender tal problemática, é preciso ter claro que onde existir violência não há poder, de modo que quaisquer imposições que façam uso da violência, ainda que em conjunto, negam o conceito de poder. É igualmente preciso compreender o que nos diz Arendt a esse respeito: "a forma extrema do poder é todos contra um, a forma extrema da violência é um contra todos" (ARENDT, 2001a, p. 35), o que nos faz recordar o papel do totalitarismo para aniquilar enormes quantidades de pessoas. Para isso, o Führer e seu pequeno grupo militar se utilizaram de instrumentos que maximizaram suas 
ações, de modo que a violência aparece aí como a "técnica maldita" incorporada nos campos de concentração e nas câmaras de gás.

A compreensão do uso da violência pelo totalitarismo nos ajuda na reflexão acerca do significado desse evento como evento de massa e de destruição de massa. O que parece um paradoxo nada mais é do que um dos principais pilares do totalitarismo. Tenhamos em conta que as massas que se encantaram com o movimento totalitário o fizeram por ausência de significado político, pois nada mais eram que um número amorfo de pessoas que "despertaram" para os absurdos de um movimento cuja estratégia era o uso da violência. Para essas massas, quando muito, essa violência significou um mal necessário, de tal modo que a destruição cruel de outro grupo, o dos judeus, não teve importância. E não a teve por esse outro grupo não pertencer ao corpo ideológico do totalitarismo.

Nesse sentido, percebe-se uma forte tendência ao autoritarismo, haja vista que aquilo que era determinado pelo líder totalitário deveria ser acatado e cumprido, o que leva à compreensão do caráter dogmático da violência totalitária. Isso se torna evidente quando um indivíduo é capaz de proferir sentenças e não ser questionado, quando suas palavras ganham contornos de determinações religiosas que não precisam ser compreendidas, mas apenas aceitas e cumpridas. ${ }^{14}$ Isso nos mostra a confusão feita por alguns teóricos a respeito da noção de poder, haja vista aceitarem que um único indivíduo incorpore tal conceito e o legitime pela violência deixando de lado as manifestações do agir em grupo.

Por Fim, no contexto dessa reflexão, para compreensão dos conceitos de violência e poder, é válida a explicitação de outros, como autoridade, vigor e força, desenvolvidos por Arendt. A autora de Origens do Totalitarismo entende o poder como aquilo que corresponde à habilidade não apenas para agir, mas para agir em concerto. O poder nunca é propriedade de um indivíduo, mas pertence a um grupo.

Quando falamos de um homem poderoso ou de uma "personalidade poderosa", já usamos a palavra "poder" metaforicamente (ARENDT, 2001a, p. 31), haja vista ser o mesmo apenas representante de um grupo que o escolheu para liderar essa pluralidade. Toda e qualquer compreensão que indique uma única pessoa como senhor do poder, como fez o totalitarismo ${ }^{15}$, descaracteriza 
o conceito de poder (ARENDT, 2001a, p. 37). Este, o poder não pode ser confundido com outras categorias como fez por muitas vezes a tradição do pensamento político. Assim, cabe destacar os limites existentes entre o poder e outras categorias como o vigor e autoridade.

O vigor seria o conceito marcado pela ausência da metáfora presente no conceito de poder, de tal modo que este "designa algo no singular, uma identidade individual; é a propriedade inerente a um objeto ou pessoa" (ARENDT, 2001a,p.37). O vigor é aquilo que caracteristicamente marca o individuo mais forte, o que não indica que mais força instaure poder, na medida em que o mais forte pode ser suplantado pela ação de muitos que se puseram o propósito de aniquilar o vigor. A força, por sua vez, segundo Arendt, devia terminologicamente indicar energia liberada, seja por fenômenos físicos ou sociais (ARENDT, 2001a, p. 37).

A autoridade, para Hannah Arendt, é uma categoria que merece atenção e cuidado: atenção em vista de sua importância histórica e cuidado em razão dos diversos significados que a mesma pode assumir. Sendo assim, Arendt conceitua autoridade como "aquilo que é inquestionável, por aqueles a quem se pede que obedeçam; nem a coerção nem a persuasão são necessárias" (ARENDT, 2001a, p.37) de tal modo que onde houver uso da violência e do consentimento já não haverá autoridade. Arendt fala de uma crise da autoridade, crise essa que se alastrou com o desenvolvimento do século XX, e ganhou contornos políticos em sua origem e natureza (ARENDT, 2001a, p. 37).

Quando Hannah Arendt chama atenção para o não uso da violência e da persuasão no tocante à compreensão do conceito de autoridade, ela está preservando o conceito de confusões teóricas. $O$ uso da violência degenera a autoridade, pois a violência exige o cumprimento da norma e o respeito hierárquico via uso da força, enquanto a autoridade se faz pela aceitação incondicional do outro. Assim, também o uso da persuasão não convém, na medida em que pressupõe igualdade das partes em referência ao discurso, o que potencialmente possibilita a quem obedece, via argumentação, desconstruir as verdades de quem manda, sendo assim, a hierarquia, própria da autoridade, estaria maculada. Assim, temos 
Visto que autoridade sempre exige obediência, ela é comumente confundida com alguma forma de poder e violência. Contudo, a autoridade exclui a utilização de meios externos de coerção; onde a força é usada, a autoridade em si mesma fracassou. A autoridade, por outro lado é incompatível com a persuasão, a qual pressupõe igualdade e opera mediante um processo de argumentação. Onde se utilizam argumentos, a autoridade é colocada em suspenso. Contra a ordem igualitária da persuasão ergue-se a ordem autoritária, que é sempre hierárquica. Se a autoridade deve ser definida de alguma forma, deve sê-lo, então, tanto em contraposição à coerção pela força como à persuasão através de argumentos (ARENDT, 2001b,p. 129).

Assim, a violência se difere dos demais conceitos por seu caráter instrumental e pelo poder de multiplicar as ações de uma forma nunca antes vista, de tal modo que a violência se apresenta como uma intervenção física de um indivíduo ou grupo contra outro individuo ou grupo:

Além disso, a intervenção física, (que foi tão utilizada pelo regime totalitário), consiste, e tem por finalidade destruir, ofender e coagir. É violência a intervenção do torturador que mutila sua vítima. Exerce violência quem tortura, fere ou mata; quem, não obstante a resistência imobiliza ou manipula o corpo do outro; quem impede materialmente o outro de cumprir determinada ação (BOBBIO et al,2004, p. 1291-1292).

\section{CONCLUSÃO}

Nosso maior objetivo com esse texto é provocar uma visita ao conceito de política a partir das abordagens de Hannah Arendt, não pretendemos ser a última voz em torno da questão. Contudo, entendemos ser da maior importância esse debate em torno da política. Nosso mundo contemporâneo guarda características protototalitárias na medida em que os indivíduos cada vez mais se isolam e assumindo uma postura de descompromisso com a coisa pública se distancia da política, a nosso ver, tais posturas fornecem terreno fértil para emergência de governos pautados na violência e arbitrariedade. Urge se ocupar da esfera pública e cuidar da polis pra evitar a emergência de tais movimentos. Segundo Arendt (apud Aguiar 2001, p, 190. In: Origens do Totalitarismo: 50 anos depois) devemos como Maquiavel externar nossa afeição pela vida pública, "Amo mais minha cidade do que minha alma" aqui o que importa é viver entre os homens, isto é, ente o coletivo. 
Assim, pretendemos deixar claro, a partir de nosso referencial teórico, que a violência pode fundar qualquer coisa, menos política. A política é sim a esfera do conflito, do dissenso. Contudo, isto não implica a destruição do outro. O outro está inscrito na pluralidade dos negócios humanos e goza dos mesmos direitos que todos embora possam pensar diferente. Portanto 0 discurso e a ação e o espaço público emergem como a tríade de sustentação da política enquanto movimento genuíno e legítimo. Nenhum poder que pretenda se personificar expressa a política.

O grande equívoco da história política do ocidente foi à busca pela personificação do poder. Sendo incompreensível como pode um povo aceitar a tirania ou dominação absoluto sobre si. Esta inclusive foi a indagação de Étiene de La Boétie sobre a questão da dominação aceita passivamente

Gostaria apenas que me fizessem compreender como é possível que tantos homens, tantas cidades, tantas nações às vezes suportem tudo de um tirano só, que tem apenas o poderio que lhes dão, que não tem o poder de prejudicá-los senão enquanto aceitam suportá-lo, e que não poderia fazer-lhes mal algum se não preferissem, a contradizê-lo, suportando tudo dele (LA BOÉTIE, 1982, p, 74).

Por fim temos, que nenhum regime ou movimento que se paute pela violência pode a este ser auferido a insígnia de político. Esta por sua vez encontra-se legitimada na ação em concerto, isto é, na argumentação e ação pública e para o interesse público. Tais asseverações nos leva a compreender que o sentido da política se estabelece na liberdade. "O sentido da coisa pública política aqui, mas não seu objetivo, é os homens terem relações entre si em liberdade, para além da força, da coação e do domínio" (ARENDT, 2002, p. 48)

\section{REFERÊNCIAS}

ARENDT. Hannah. Origens do Totalitarismo. 8.ed. Tradução Roberto Raposo. Rio de Janeiro: Companhia das Letras, 1998.

. Sobre a Violência. Tradução André Duarte. Rio de Janeiro: RelumeDumará, 2001a.

. Entre o Passado e o Futuro. 2. ed. Tradução Mauro W. Barbosa de Almeida. São Paulo: Perspectiva, 2001b. 
. O que é a Política? Fragmentos de obras póstumas compilados por Ursula Ludz. Trad. Reinaldo Guarany, $3^{a}$ edição, Rio de janeiro, Bertrand Brasil, 2002.

ASSY, Bethânia. Eichmann, Banalidade do Mal e Pensamento em Hannah Arendt. In: BIGNOTTO, Newton; MORAES, Eduardo Jardim de (Org.). Hannah Arendt: Diálogos, Reflexões e Memórias.Belo Horizonte: Ed. UFMG, 2001.

BOBBIO, Norberto et al. Dicionário de Política. Brasília: Ed. UnB, 2004

DUARTE, André. O Pensamento à Sombra da Ruptura: Política e Filosofia em Hannah Arendt. São Paulo: Paz e Terra, 2000.

LAFER, Celso. Hannah Arendt: Pensamento, Persuasão e Poder. Rio de Janeiro: Paz e Terra, 1979.

A Reconstrução dos Direitos Humanos: Um Diálogo Com o

Pensamento de Hannah Arendt. 4. ed. São Paulo: Companhia das Letras, 2001.

LA BOETIE. Etiene. Discurso da servidão voluntária. São Paulo, Ed. Brasiliense, 1982.

AGUIAR. Odílio. [et al.] . Origens do Totalitarismo: 50 anos depois. Rio de Janeiro, Relumé Dumara. 2001

\footnotetext{
${ }^{1}$ Mestre em Filosofia-UFC. Professor da Universidade Federal Rural de Pernambuco-UFRPE. Membro do Grupo de Pesquisa Labor-UFC.

${ }^{2}$ Mestre em Economia-UFC. Mestre em Políticas Públicas-UECE. Professor da Universidade Federal Rural do Semiárido-UFERSA.
}

${ }^{3} \mathrm{O}$ caráter profético da propaganda totalitária se mostra a partir do anúncio de uma pretensa "verdade" assumida pelas massas. Os mecanismos de terror e violência logo atuam para tornar real aquilo que foi predito, como forma de demonstrar a realização da profecia, e apresentam como única justificativa a idéia de que "aconteceria de qualquer forma".

${ }^{4}$ Aqui chamamos a atenção para o fato da dignidade humana, isto é, para o indivíduo que se coloca no mundo como gente que é capaz de transformação. Contudo, essa violência produzida nos campos de concentração impede esse homem de ser e o anulam de forma covarde e brutal, reduzindo-o a um nada.

${ }^{5}$ É preciso ter claro o papel central do partido que aqui é central, na medida em que é nele que se encontra todo o processo de doutrinação e enquadramento do idealismo absurdo, acalentado pela ideologia do terror.

${ }^{6}$ Quando falo de humano construído nos indivíduos, refiro-me à compreensão de Hannah Arendt acerca da natureza mutável, onde o que temos de humano não é algo inerente e eterno, mas uma construção de artifícios, produzidos pela liberdade, pelo discurso e pela ação, de tal 
modo que a experiência dos campos de concentração aniquila esses artifícios. Sendo assim, a legalidade, o respeito à pluralidade e à cidadania deixam de imprimir sentido à dignidade humana de modo que o homem se reduz a um ser natural desumanizado.

${ }^{7}$ Basta lembrarmos-nos do despotismo esclarecido, segundo o qual tiranos foram capazes de abolir torturas e julgamentos sumários, por terem ouvido o outro. Nesse sentido, percebemos a novidade totalitária que entende o outro como algo a ser descartado, caso não comungue de seus ideais. $O$ totalitarismo aparece para a história da humanidade como um regime negador do discurso e da ação, categorias centrais para a colocação do outro no espaço público. A cada prisão, expurgo ou assassinato, o regime totalitário traz à tona o princípio da descartabilidade que torna a produção sistemática de cadáveres uma prática constante.

${ }^{8} \mathrm{O}$ trabalho desenvolvido pelo Nazifascismo vislumbrava o desmantelamento da esfera pública por meio da destruição de elementos-chave como a liberdade.

${ }^{9}$ Auschwitz é a grande representação disso, o campo de concentração polonês, que enquadrou centenas de judeus como se confina gado, submetendo-os às maiores atrocidades. Auschwitz aparece para o mundo como a maior expressão do requinte da crueldade do regime totalitário. Para Arendt, foi o momento de despertar para o problema: "[...] é como se um abismo se abrisse". As primeiras notícias sobre os campos de extermínio nazistas, diz um dos sobreviventes de Auschwitz, primo Levi, no seu prefácio a I sommersi e i salvati (1986): "começaram a difundir-se no ano crucial de 1942. Eram notícias vagas, mas convergentes entre si: delineavam um massacre de proporções tão amplas, de uma crueldade tão extrema, de motivação tão intricada que o público tendia a rejeitá-las em razão do seu próprio absurdo. É significativo como essa rejeição tenha sido prevista com muita antecipação pelos próprios culpados; muitos sobreviventes [...] recordam que os SS se divertiam avisando cinicamente os prisioneiros: 'Seja qual for o fim desta guerra, a guerra contra vocês nós ganhamos; ninguém restará para dar testemunho, mas mesmo que alguém escape, o mundo não dará crédito. Talvez haja suspeitas, discussões, investigações de historiadores, mas não haverá certezas, porque destruiremos as provas junto com vocês. E ainda que fiquem algumas provas e sobreviva alguém, as pessoas dirão que os fatos narrados são tão monstruosos que não merecem confiança: dirão que são exageros da propaganda aliada e acreditarão em nós, que negaremos tudo, e não em vocês. Nós é que ditaremos a história dos Lager' (A tradução francesa desse texto, realizada por Sylvie Courtine-Denamy, foi publicada, em 1980, no no 06 da revista Esprit [p. 19-40] e disposta no artigo "A natureza do Totalitarismo: o que é compreender o totalitarismo" de Theresa C. Magalhães, publicado, por sua vez, na obra AGUIAR et al., 2001, p. 58. [As nossas referências são desse artigo]).

${ }^{10}$ Para Arendt, a política se baseia na pluralidade e na convivência com o diferente (Cf. ARENDT, 2002, p. 21). Se constatarmos que a marca da violência totalitária foi a perseguição a judeus e a outras minorias, podemos concluir que essa violência acalentava o desejo do 
governo dos iguais. Sendo assim, a produção sistemática de cadáveres passa a ser uma meta do poder que se instaura pela violência.

${ }^{11}$ Esse conceito é fruto do espanto de Arendt mediante as palavras finais de Eichman. Aqui, Arendt parece chegar à consciência do que significava, no esquema totalitário, a expressão "tudo é possível", pois as mesmas conduziram pessoas a ser tratadas como supérfluas e descartáveis (Cf. ARENDT, 2002, p. 111).

12 Eichmann fora oficial da Gestapo no comando da segurança do Reich, sob as ordens de Himmler. Não fora oficial de alta patente, mas cabia-lhe a responsabilidade de dirigir a seção que lidava com os judeus, então considerados adversários do estado. Isso significava que ele se encarregava de organizar as deportações em massa e as evacuações de judeus, inclusive de levá-los diretamente para os campos de extermínio.

${ }^{13} \mathrm{O}$ fato de Arendt conceituar o poder como uma capacidade de agir em conjunto não significa que ação em conjunto por si só instaure poder, pois deve sempre ser levado em consideração que, sozinha ou em grupo, a violência não deve compor a ação, sob pena de cairmos na compreensão da política como luta pelo poder.

${ }^{14} \mathrm{O}$ dogma no esquema religioso aparece como uma verdade de fé. A verdade de fé é compreendida desde a filosofia medieval como verdade revelada e, enquanto verdade revelada, não carece de compreensão, mas de aceitação. A frase que melhor definiria o conjunto de pensadores adeptos dessa corrente no mundo medieval é: "creio porque é absurdo". A postura das massas e do escalão bélico totalitário se encaixava nesse paradigma na medida em que não sentiam necessidade de compreender o que era determinado, mas apenas cumpriam a ordem manifesta na sentença, mesmo que isso significasse $o$ assassinato de inocentes. Basta lembrarmos das palavras de Eichmann nos interrogatórios de seu julgamento: "apenas cumpria ordens" (Cf. DUARTE, 2000, p. 65).

${ }^{15}$ Aqui temos o contraponto, da noção política de Arendt, para a maneira totalitária de governar que pensa o poder de forma concentrada e autoritária.

RECEBIDO EM: outubro/2013

APROVADO EM: novembro/2013 